Sammelsurium ähnlich den in den letzten Jahren populär gewordenen Listenwerken à la Schott. Feldkamps Anspruch, es könne ein Wegbegleiter durch den Bundestag sein (S. 5), wird so nicht eingelöst. Hinzu kommt, dass es einige Ungenauigkeiten gibt: So zählt die Reichstagskuppel seit 2000 pro Jahr zwischen 585.605 und 744.463 Besucher, die bei Feldkamp im Fließtext zu fast einer Million pro Jahr werden (S. 198). Es werden außerdem keine Quellen angegeben, was bei der Fülle an statistischen Informationen wünschenswert gewesen wäre. Es hätte zum Beispiel interessiert, woher die Zahlen über die Größe von Parlamentsbibliotheken in Europa stammen (S. 202). Schließlich ist die Gliederung nicht stimmig. Abgeordnete werden beispielsweise in drei Abschnitten behandelt (Die Mitglieder des Bundestages; Aus dem Arbeitsalltag eines Abgeordneten; Haushalt und Diäten).

Die Veröffentlichung hätte mehr systematische Auswahl und Recherche verdient gehabt. Der Ansatz, weit verstreutes Wissen zu bündeln, ist lobenswert; doch er überzeugt in dieser Umsetzung nicht vollständig. Vielleicht führt auch der Titel in die Irre, der Hoffnung auf einen knappen und systematischen Wegweiser durch den Bundestag weckt. Zudem verwundert, dass aus den angekündigten 100 Fragen und Antworten tatsächlich 121 werden.

Beide Publikationen führen somit auf zwei unterschiedlichen Wegen an den Bundestag heran. Auf eine Monographie für eine größere Leserschaft zu Deutschlands Parlament, die sich auch der Dilemmata im Parlamentsverständnis annimmt ${ }^{4}$, muss allerdings weiter gewartet werden.

Franziska Höpcke

4 Vgl. Gerhard Loewenberg, Paradoxien des Parlamentarismus. Historische und aktuelle Gründe für Fehlverständnisse in Wissenschaft und Öffentlichkeit, in: ZParl, 38. Jg. (2007), H. 4, S. 816 -827 .

\title{
Lesenswertes Brevier zur parlamentarischen Symbolik
}

Feldkamp, Michael F. und Dirk Kunze: Mit Frack im Parlament. Ein Beitrag zur parlamentarischen Kultur und politischen Symbolik im Deutschen Bundestag, Nomos Verlagsgesellschaft, Baden-Baden 2009, 79 Seiten, € 19,90.

Das parlamentarische Protokoll der Bundesrepublik verzichtet auf übermäßigen Pomp und ausladende Gesten der Macht. Der Bundestag versteht sich als Arbeitsparlament, und dieses Selbstverständnis als geräuschlos arbeitender Gesetzgeber soll auch in der staatstragenden Symbolik zum Ausdruck kommen. Auch nach dem Umzug des Parlaments in das geschichtsgesättigte Reichstagsgebäude triumphiert im Plenarsaal die kühle Routine sachorientierter Parlamentsarbeit über aufwendiges Staatstheater. Trotz dieser Verzichtsästhetik hat der Parlamentsbetrieb der Bundesrepublik seine eigene Formensprache und Darstellungsformen der repräsentativen Demokratie entwickelt. Dazu gehören unter anderem die Saaldiener des Bundestages mit ihrem Frack, die zu einem „unverwechselbare[n] Bestandteil des parlamentarischen Alltags im Bundestag und damit zu einem Symbol der parlamentarisch-repräsentativen Demokratie in der Bundesrepublik avanciert“" sind (S. 9). 
Michael F. Feldkamp, ausgewiesener Kenner des deutschen Parlamentarismus, und Dirk Kunze, der selbst als Saaldiener tätig war, haben ein sehr lesenswertes Brevier zur Entstehungsgeschichte und Bedeutung des Parlamentsfracks geschrieben. Mit ihrer kleinen Abhandlung - reichhaltig mit Bildern aus sechzig Jahren Parlamentsgeschichte illustriert werfen die Autoren Licht auf einen besonderen Aspekt der Symbolsprache des Bundestages.

Die Frauen und Männer in der würdevollen Amtskleidung sind ein integraler Teil jeder Parlamentsdebatte und weit mehr als nur dienstbare Geister im Hintergrund. Ihnen obliegt es, die farbigen Stimmkarten der Abgeordneten zu kontrollieren, Tagesordnungen, Beschlussempfehlungen und andere Schriftstücke im Saal zu verteilen sowie jedem Redner ein frisches Glas Wasser bereitzustellen. Wenn nach einem langen Tag im Plenum etliche Drucksachen und Aktennotizen in den Stuhlreihen zurückbleiben, räumen die Saaldiener diese schriftlichen Reste erhitzter Wortgefechte am Abend zusammen.

Die parlamentarischen Saaldiener gab es zwar schon in den Anfängen der jungen Bundesrepublik, doch trugen sie damals noch keine einheitliche Uniform. Lediglich „Zwei verbindliche Kleidervorschriften“ (S. 33) statuierten, dass jeder Saaldiener eine Krawatte zu tragen hatte sowie eine grüne Binde am linken Oberarm mit der Aufschrift „Hausordnungsdienst“. Während der Einführung einer neuen Dienstkleidung für die Saaldiener unter Bundestagspräsident Hermann Ehlers noch etliche Hindernisse im Weg standen, setzte sein Nachfolger, Eugen Gerstenmaier, einige Veränderungen ins Werk. Ihm missfiel die bisherige Bekleidung der Saaldiener aufgrund ihrer mangelnden Würde und war daher der Meinung - wie er viele Jahrzehnte später in seinen Lebenserinnerungen bekundete -, die Saaldiener „sollten ihre Schaffnermonturen gegen Fräcke tauschen“ (S. 44). Vorbild für deren Einführung zum Jahreswechsel 1954/55 war der Frack, den die Saaldiener beim französischen Botschafter trugen. Nur der Leiter der Saaldiener, der sogenannte Platzmeister, trug damals aus Gründen der Unterscheidbarkeit als einziger eine hellbeige Weste. Dieser Umstand führte zu dem lakonischen Presseecho, der Platzmeister sei der einzige im Saal mit einer „weißen Weste“ (S. 47). Mit der neuen Amtstracht, die damals in den Plenarsaal Einzug hielt, war der Bundestag nicht nur stilbildend für die politische Mode der jungen Republik, sondern fungierte auch „als Trendsetter der Bonner Herrenmode“ (S. 48).

War das Amt des Saaldieners über Jahrzehnte eine reine Männerdomäne, wurde mit der Wahl Annemarie Rengers zur Bundestagspräsidentin im Dezember 1972 die Forderung erhoben, auch Frauen als Saaldiener in Bonn zuzulassen. Es dauerte dann jedoch noch viele Jahre, bis die ersten Saaldienerinnen ihre Arbeit aufnahmen. Auch der modische Aspekt löste etliche Diskussionen aus, da die Vorstellung von Frack tragenden Frauen im Plenum nicht mehrheitsfähig war. Schließlich einigte man sich auf ein Kostüm bestehend aus einer „mitternachtsblauen“ Jacke (S. 61), die aus dem gleichen Stoff gefertigt war wie der Frack der Saaldiener. Am 19. Januar 1989 kam dieses Kleidungsstück erstmalig zum Einsatz. Als neu gewählte Bundestagspräsidentin betonte Rita Süssmuth in ihrer Eröffnungsrede, dass auf den Tag genau vor 70 Jahren Frauen zum ersten Mal in Deutschland wählen durften. Im Jahr 2008 waren über 70 Prozent der Saaldiener Frauen, was dazu geführt hat, dass der klassische Parlamentsfrack ein wenig aus dem öffentlichen Erscheinungsbild des Bundestages verdrängt worden ist. Dennoch ist er bis heute ein außergewöhnliches Kleidungsstück des Parlamentsalltags geblieben und ist somit längst „ein Markenzeichen des Bundestages geworden und steht als Chiffre für die Würde des Hohen Hauses“ (S. 65). 